University of Wollongong

Research Online

Faculty of Engineering - Papers (Archive)

Faculty of Engineering and Information

Sciences

$1-1-2001$

\title{
Cubic beam elements in practical analysis and design of steel frames
}

Lip H. Teh

University of Wollongong, Iteh@uow.edu.au

Follow this and additional works at: https://ro.uow.edu.au/engpapers

Part of the Engineering Commons

https://ro.uow.edu.au/engpapers/630

\section{Recommended Citation}

Teh, Lip H.: Cubic beam elements in practical analysis and design of steel frames 2001, 1243-1255.

https://ro.uow.edu.au/engpapers/630

Research Online is the open access institutional repository for the University of Wollongong. For further information contact the UOW Library: research-pubs@uow.edu.au 


\title{
Cubic beam elements in practical analysis and design of steel frames
}

\author{
Lip H. Teh \\ Department of Civil Engineering, University of Sydney, NSW 2006, Australia
}

\begin{abstract}
This paper discusses various issues in the use of cubic beam elements for computer structural analysis/design of steel frames. It is pointed out that the concern expressed in recent literature regarding the number of cubic elements required to model a steel member is not justified, and that the inaccuracy of one cubic element in Euler buckling analysis of a simply supported column is largely irrelevant to the second-order elastic analysis/design or advanced analysis of steel frames. The sources of inaccuracy of the cubic element are elucidated. It is also explained that the plastic-zone analysis method is not so inefficient as was previously believed. The spatial cubic element is shown to be capable of accurately accounting for the coupling between axial, flexural and torsional deformation modes. It is concluded that for the purposes of second-order elastic analysis/design and advanced analysis of $2 \mathrm{D}$ and $3 \mathrm{D}$ steel frames, the well-documented cubic element is a versatile and efficient choice.
\end{abstract}

Keywords: advanced analysis; beam columns; buckling analysis; cubic elements; secondorder analysis; space frames

\section{Introduction}

In the past few decades, there has been a debate regarding the merits of the cubic element visa-vis the stability function based beam-column for steel frame analysis. The cubic element is a finite element formulated using an energy principle and assumed shape functions for the displacement fields [1], and its stiffness matrices are widely available [2-11]. On the other hand, a stability function based beam-column is derived by solving the differential equations of equilibrium assuming small deformations [12-17]. The cubic element is generally known to be inferior to the stability function based beam-column in Euler buckling analysis of columns, and, widely but incorrectly, in second-order elastic analysis of steel frames, since it is believed that more cubic elements are required to model a given frame to achieve comparable accuracy. Conversely, it has been pointed out that the cubic element used for 
plane frame analysis is more readily extended to three-dimensional frame analysis accounting for the coupling between axial, flexural and torsional deformation modes, and to materially nonlinear analysis [9, 17-18]. Furthermore, the stability function based beam-column may encounter numerical difficulty under a small axial force [19]. In response to the perceived shortcomings of the cubic element and the conventional stability function based beamcolumn, various formulations have been proposed in the literature [19-22].

As rational frame buckling analysis and second-order elastic analysis/design using computer are fast becoming entrenched in the structural engineering profession, it is desirable that proper understanding of the merits and demerits of various beam elements or beam-columns is established among structural engineers in order to help prevent a 'black box' mentality. A good knowledge of the capabilities and the limitations of the element used for the buckling analysis or the second-order elastic analysis will help the engineer design a safe structure with more confidence. On the other hand, undue concern regarding the limitations of an element may lead to inefficiency in structural analysis as too many elements or unnecessary manipulations are used to model the structure, or result in over-conservative design as the computer analysis results are "factored" in various ways to account for the perceived inaccuracy of the element. As pointed out by McGuire [23], the use of computer programs for structural analysis/design places more rather than less responsibility on the engineer.

In this paper, it will be explained that the concern expressed in recent literature regarding the need to employ several cubic elements for Euler buckling analysis of a column is misplaced, is often immaterial to frame buckling analysis, and is largely irrelevant to the second-order elastic analysis/design and the advanced analysis/design procedures. It will also be demonstrated that the perceived shortcoming of the cubic element in second-order elastic analysis is not justified. The feasibility of using the cubic element for the plastic-zone analysis of steel frames is also discussed. Brief description of the advanced analysis method of steel frames is included in this paper to facilitate the discussion.

This paper puts forward a strong case for the use of the well-documented cubic element in the analysis/design of steel frames, whether for linear buckling analysis, second-order elastic analysis, second-order inelastic analysis based on the plastic-zone approach, out-of-plane buckling analysis, or general three-dimensional structural analysis. For each type of analysis, examples are presented to illustrate the points made in the paper. 
The thrust of this paper is based on two principles. Firstly, for a newly proposed element or analysis method to replace the status quo, it has to offer practical advantages which are significant enough to offset the inconvenience and risk arising from the change. In addition to this requirement, the new element or analysis method should not bring with it intrinsic demerits absent in the status quo. Secondly, no matter how established a method of analysis/design is, once it is known to be deficient and a significantly better alternative becomes available and accessible, efforts should be made to encourage the profession towards the adoption of the superior alternative.

\section{Linear buckling analysis}

Perhaps the best known shortcoming of the cubic element is its inability to predict the Euler buckling load of a simply supported column with high accuracy when only one such element is used to model the structure. This shortcoming has been cited in recent literature as a reason against the use of the cubic element in structural analysis/design of steel frames, as it is thought to increase the complexity of structural modelling and the cost of computation [21, 22]. Chan \& Zhou [21] and Liew et al. [22] point to the Euler buckling problems of axially compressed columns such as those depicted in Fig. 1. The three columns on the left are braced members, while those on the right are unbraced members.

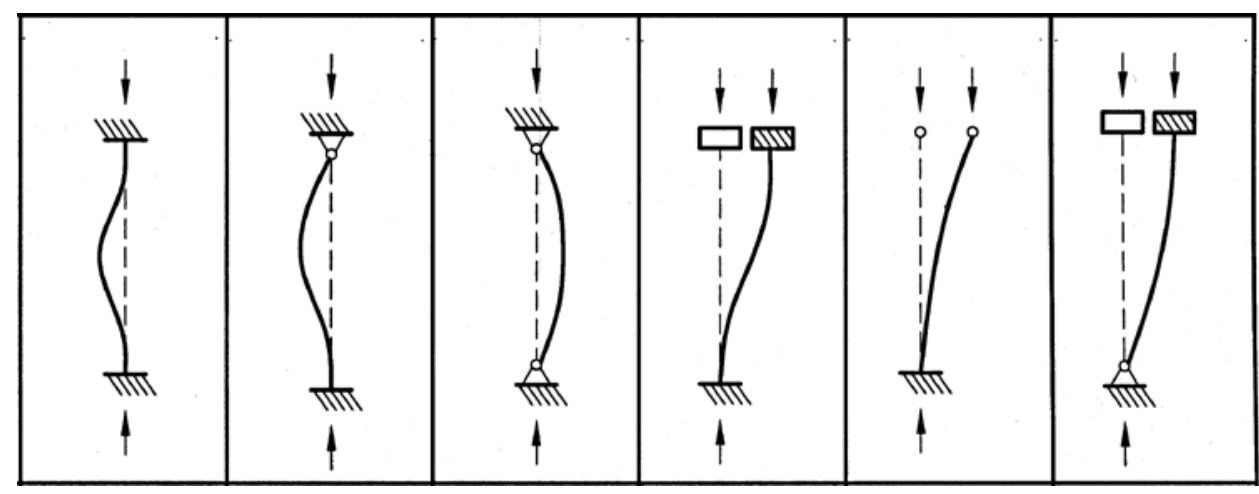

Fig. 1 Columns with standard boundary conditions

The writer would like to point out that at most only two cubic elements are required to accurately predict the Euler buckling load of a braced member, and only one is required for an unbraced member. The errors of using two cubic elements for the built-in column and for the simply supported column are less than $0.5 \%$, while that for the propped column is less than $2 \%$ [24]. For each of the unbraced columns, the error of using one cubic element is less 
than $1 \%$. The reason for this excellent performance of the cubic element is explained in Appendix I.

In fact, it is often feasible to use only one cubic element per column for the linear buckling analysis of a multi-storey multi-bay frame, for which computational expense may become an issue. An illustrative example of such a case is the diagonally braced ten-storey plane rigidjointed frame shown in Fig. 2. For the purpose of illustrating the point made previously, no units are used and the column sizes and the column loads are assumed to be uniform. The variables $E, I$ and $A$ denote the Young's modulus, the second moment of area and the crosssection area, respectively. The column bases are assumed to be fixed and the diagonal braces are pin-ended.

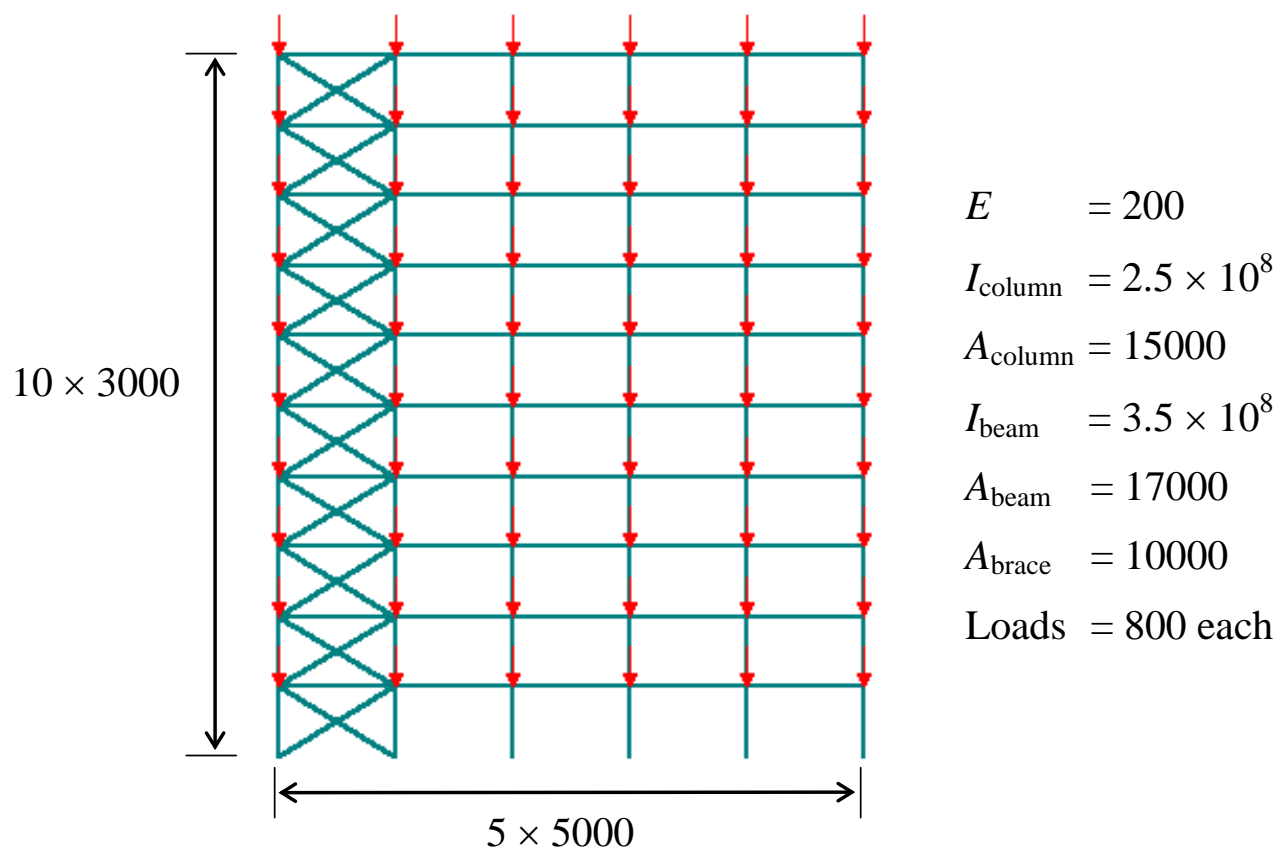

Fig. 2 Diagonally braced ten-storey five-bay plane frame

Two models are used for linear buckling analyses of the frame. In the first model, only 1 cubic element per member is used. In the second model, 5 cubic elements per column and 2 cubic elements per beam are employed. The buckling load factors were found to be 12.1 and 12.0, respectively. The frame buckling mode is shown in Fig. 3. Here it can be seen that using only 1 cubic element per member leads to a highly accurate result. It is also noteworthy that the effective length factor of the right-most base column is only 0.75 , as computed from the rational buckling analysis. This value is close to the effective length factor of a propped column (an example of braced members), which is 0.7 . 


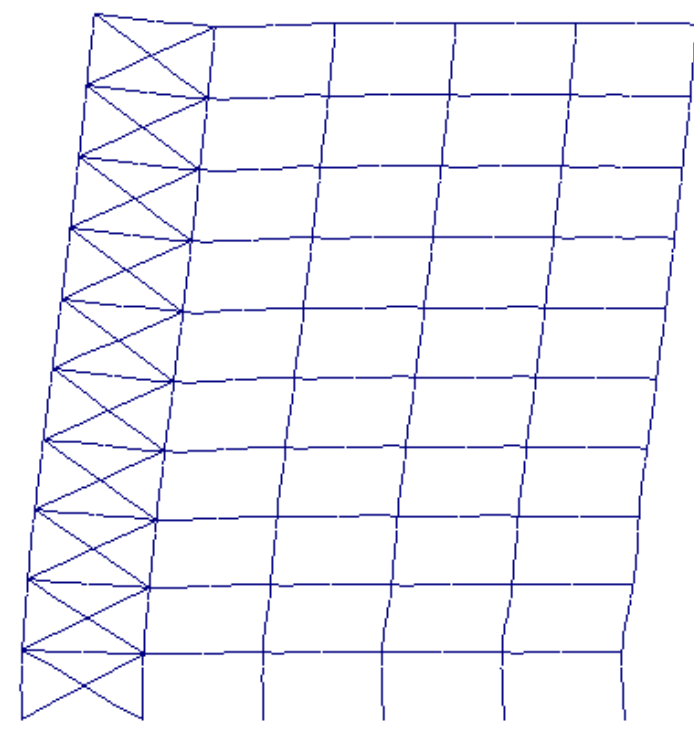

Fig. 3 Buckling mode of ten-storey five-bay plane frame

As a matter of interest, performed on a Pentium $166 \mathrm{MHz}$ desktop computer, the linear buckling analysis of the second model with a total of 420 elements was completed in ten seconds. Therefore, even if two elements are used to model each of the more critical columns, it will lead to little penalty in analysis time on a modern desktop/laptop computer.

It can be seen from the preceding expositions that the concern expressed in recent literature regarding the inaccuracy of one cubic element in Euler buckling analysis of a simply supported column is largely misplaced. Furthermore, the fact that the easily overcome shortcoming of the cubic element is well documented should be a reason 'for' rather than 'against' its use, although some authors considered this well-known shortcoming a major pitfall [22]. A pitfall is in fact more likely with a newly proposed element or beam-column.

\section{Second-order elastic analysis}

Some authors have extrapolated the shortcoming of the cubic element in Euler buckling analysis of a braced member to geometrically nonlinear analysis (second-order elastic analysis) of frames. Their rationale is that since the cubic element cannot predict the Euler buckling load of a simply supported column with high accuracy when only one element is used, it cannot be expected to be good for second-order elastic analysis of frames. However, the induction is false as explained in Appendix I. The contradictory evidence in the literature of the inaccuracy of the cubic element in second-order elastic analysis of frames is discussed in the following paragraphs. 
It has been widely believed for many years in the structural engineering literature that more than one cubic element per beam-column are required for accurate second-order elastic analyses of framed structures. This incorrect belief appears to have been caused by the inadvertent use of the Updated Lagrangian (henceforth denoted "UL”) cubic element which assumes a straight configuration at the current state, to which the incremental displacements and the element forces are referred. This assumption is illustrated in Fig. 4 and Fig. II.1 of Appendix II. Configuration $\mathrm{C}_{0}$ is the initial undeformed state of the beam element, and $\mathrm{C}_{1}$ is the current (intermediate) state under a partial application of the structure loads. In predicting the next configuration $\mathrm{C}_{2}$ resulting from a load increment applied to the current configuration $\mathrm{C}_{1}$, the tangent stiffness matrix of the element at $\mathrm{C}_{1}$ is determined using the assumption that the element is straight, even though it is actually deformed. This tangent stiffness matrix is also used in the incremental force recovery procedure $[5,7,10]$.

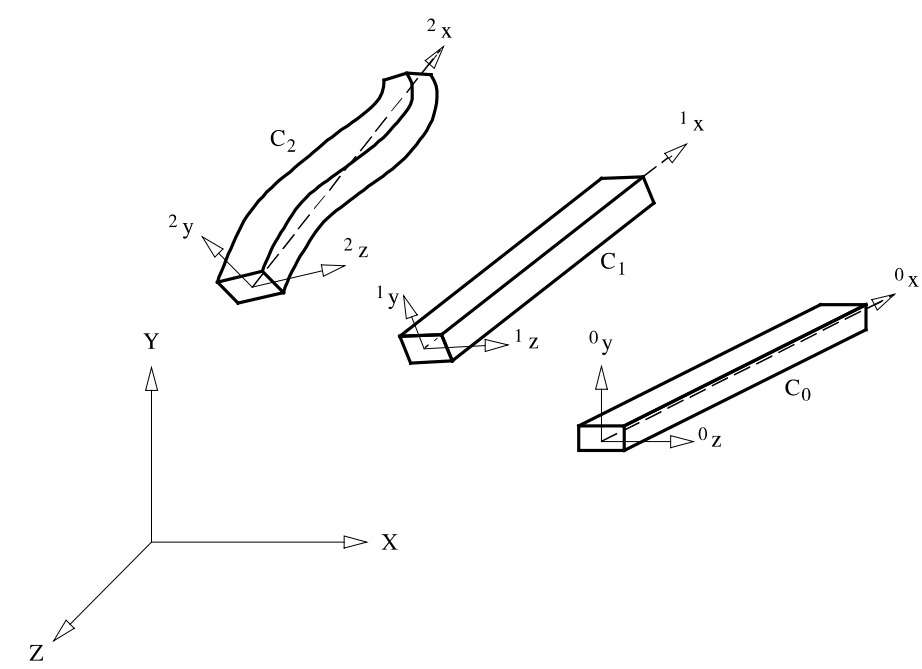

Fig. 4 Assumption of a straight configuration at the intermediate state $\mathrm{C}_{1}$

Such a cubic element, the tangent stiffness matrix of which is shown in Appendix II, was described by Porter \& Powell [5], who explicitly stated the assumption. However, this assumption does not appear to be recognised by many later researchers who described essentially the same UL cubic element with varying degrees of approximation introduced into their formulations, except for Gattass \& Abel [7]. As demonstrated by Teh \& Clarke [25], the assumption of a straight configuration at the actually deformed reference state $C_{1}$ leads to significantly poorer performance of the cubic element in the second-order elastic analysis of the Williams' toggle [26] depicted in Fig. 5. 


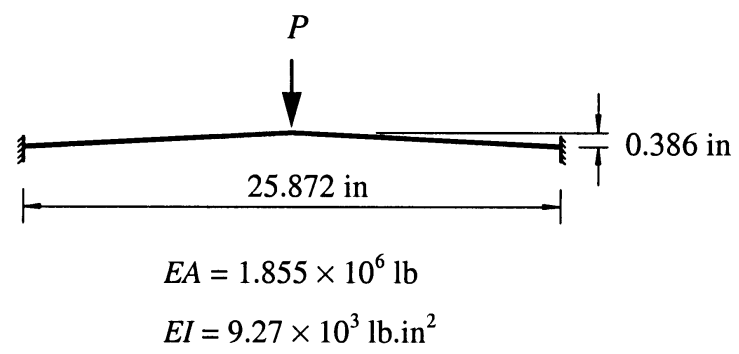

Fig. 5 Williams’ toggle [26]

Teh \& Clarke [25] stated that eight UL cubic elements which assume a straight configuration at the reference state are required to accurately trace the nonlinear equilibrium path of the Williams' toggle. However, Teh \& Clarke [25] also mentioned that only one UL cubic element is required to achieve high accuracy if the deformed shape of the element at the reference state is taken into account in determining the tangent stiffness matrix [27-28]. In fact, the assumption of a straight configuration at the deformed reference state is irrelevant to the Co-rotational (henceforth denoted "CR") formulation, in which the initial undeformed reference configuration continuously translates and rotates with the element. This is illustrated in Fig. III.1 of Appendix III, where the secant stiffness relations of the CR cubic element [4] are also given.

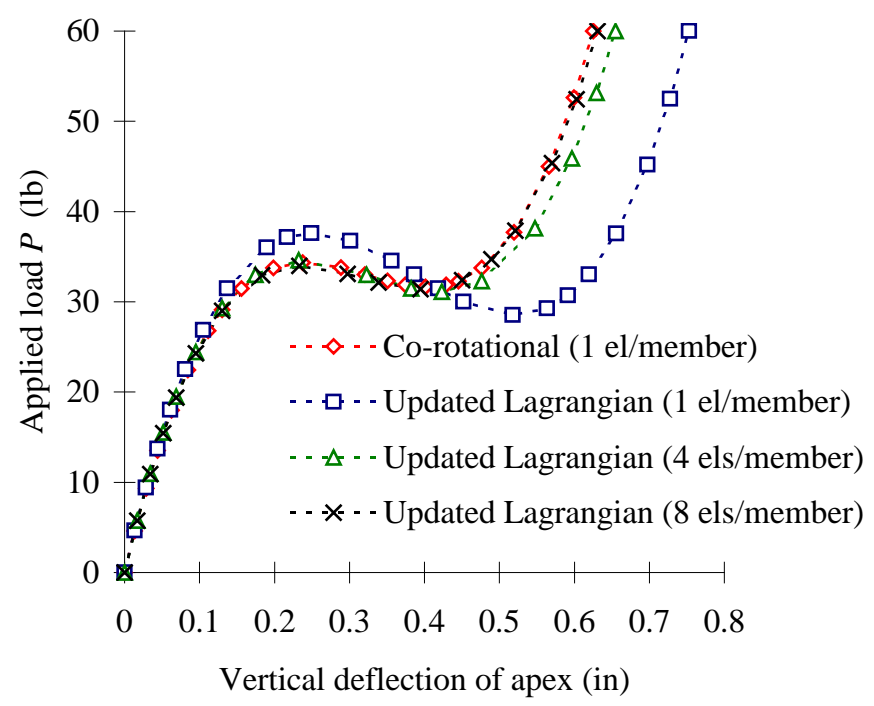

Fig. 6 Load-deflection graphs for Williams’ toggle [25]

Figure 6 shows the load-deflection graphs for the Williams toggle obtained using one CR cubic element and one, four and eight UL cubic element which is impaired by the forementioned assumption. The modified arc-length method [29] and the minimum residual 
displacement method [30] were used to negotiate the load limit points. The equilibrium path traced by one CR cubic element coincides with that traced by Williams [26].

Very recently, Liew et al. [22] stated that eight cubic elements are required to trace the nonlinear equilibrium path of the Williams' toggle. Liew et al. [22] also claimed that their proposed UL stability-function based element is superior to the cubic element because "it considers both the $P-\delta$ effect and member bowing effect”. However, both the $P-\delta$ and the member bowing effects [31] mentioned are considered even in the UL formulation which assumes a straight configuration of the cubic element at the reference state, as detailed by Gattass \& Abel [7]. A UL cubic element or beam-column that accounts for the bowing effect but neglects the deformed shape at the reference state leads to inaccurate results when one element per member is used. As implied previously, UL cubic elements which account for the deformed shape at the reference state were presented by Gattass \& Abel [27] and Clarke [28].

One interesting point to note is that a linear stiffness matrix, if cast in a Co-rotational framework [1], performs better than the impaired UL cubic element described in Appendix II. This phenomenon has led to the confusion why the impaired UL cubic element, which includes the geometric stiffness matrix, does not perform better than the CR linear element in geometrically nonlinear analyses of frames [32].

The excellent performance of the cubic element in second-order elastic analysis of framed structures also extends to the Euler buckling analysis of a cantilevered column or the bifurcation analysis of a framed structure that has been modified into a geometrically nonlinear analysis problem via the introduction of geometric imperfections, perturbation loads, or perturbation displacements [33]. An example of such a case is quoted from Liew et al. [22] for the column depicted in Fig. 7. In order to initiate the post-buckling path, a small perturbation moment is applied to the column top. It can be seen from Fig. 8 that one cubic element is sufficient to identify the Euler buckling load accurately, and within the confines of practical usefulness, also traces the post-buckling path with good accuracy. Note that the tip displacement $w$ is a vertical displacement as defined in Fig. 7, so a value of $w / L$ equal to 0.2 represents a very excessive deformation of the column. It should also be noted that the cubic element used by Liew et al. [22] to trace the post-buckling path is the UL element which assumes a straight configuration at the reference state. Furthermore, notwithstanding the contention of Liew et al. [22], it is evident from Fig. 8 that the use of two such cubic elements compares favourably against the use of two elements proposed in their paper. 


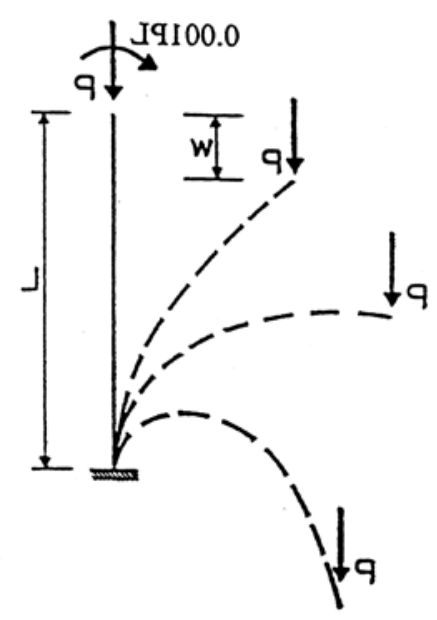

Fig. 7 Pseudo-bifurcation analysis of an axially compressed column [22]

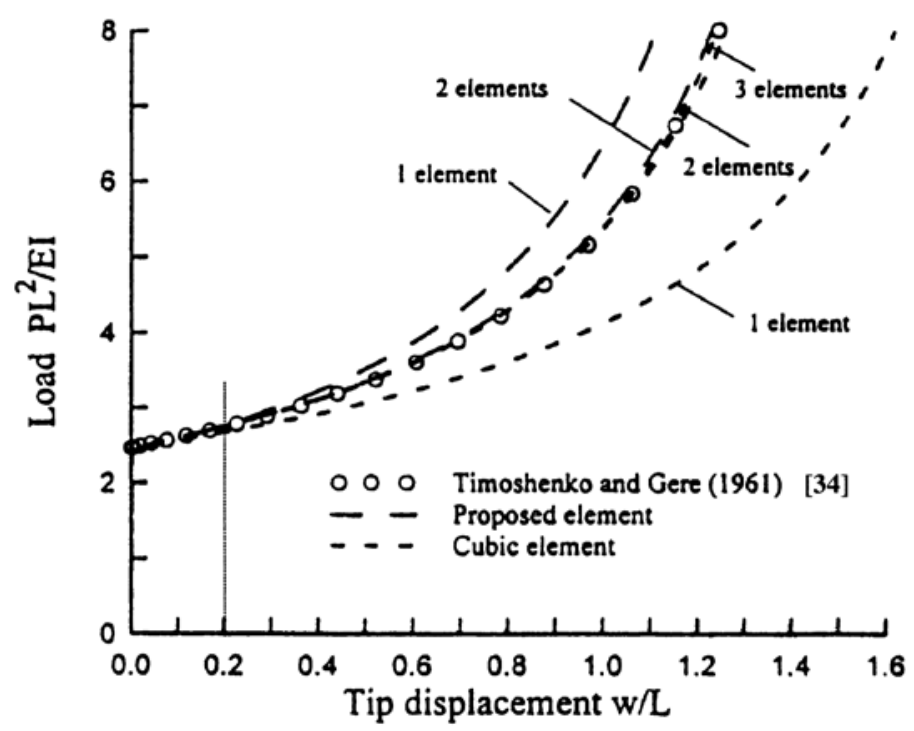

Fig. 8 Post-buckling paths for axially compressed column [22]

The accuracy of the cubic element in determining the second-order member forces of a framed structure is demonstrated using the example depicted in Fig. 9, which is similar to the structure discussed previously but for the transverse shear force. The seemingly simple structure is in fact a benchmark problem proposed by Hancock [35] for the verification of nonlinear structural analysis software. This example, for which the classical solutions are available, should be rigorous enough for beam elements used to analyse steel framed structures. Two models were used for the present second-order elastic analyses of the column, employing 1 and 2 CR cubic elements, respectively. Table 1 compares the solutions for the bending moment at the column base obtained using the classical approach, the stability function based beam-column, and the two cubic element models. It can be seen that 
the second-order elastic analysis results are close to each other, even when the applied axial load $P$ is close to the Euler buckling load $P_{\mathrm{b}}$. The largest error incurred by using 1 cubic element to model the column is less than $5 \%$.

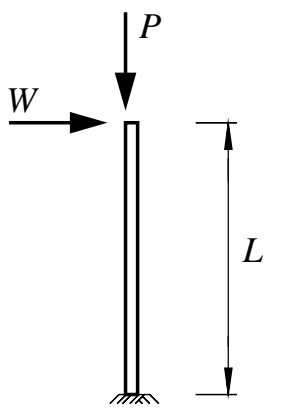

$E=200 \mathrm{kN} / \mathrm{mm}^{2}$

$I=100 \times 10^{6} \mathrm{~mm}^{4}$

A $=10 \times 10^{3} \mathrm{~mm}^{2}$

$L=5000 \mathrm{~mm}$

$W=10 \mathrm{kN}$

$P_{b}=1974 \mathrm{kN}$

(a) Data used in Second Order Analysis

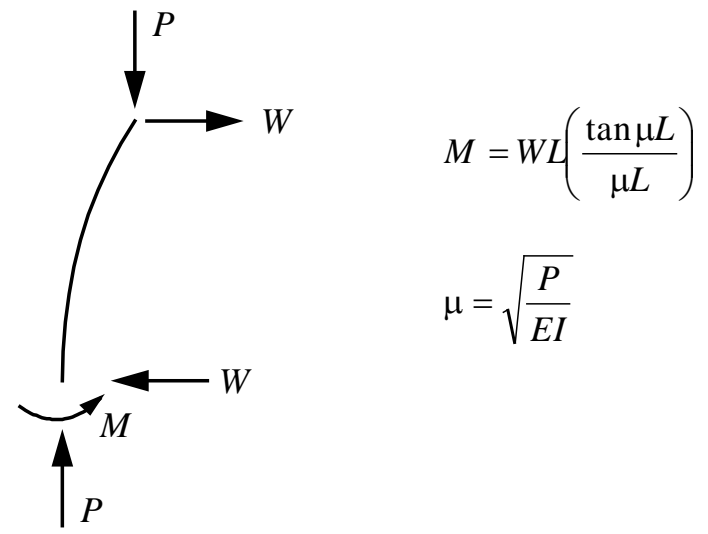

(b) Trahair Classical Solution

Fig. 9 Second-order moment of a cantilevered column

Table 1. Second-order moments at the base of cantilevered column

\begin{tabular}{|c|c|c|c|c|}
\hline $\begin{array}{c}P \\
(\mathbf{k N})\end{array}$ & $\begin{array}{c}\text { Classical } \\
(\mathbf{k N m})\end{array}$ & $\begin{array}{c}\text { Beam-column } \\
(\mathbf{k N m})\end{array}$ & $\begin{array}{c}1 \text { Cubic element } \\
(\mathbf{k N m})\end{array}$ & $\begin{array}{c}2 \text { Cubic elements } \\
\text { (kNm) }\end{array}$ \\
\hline 500 & 63.9 & 63.9 & 63.9 & 63.9 \\
\hline 1000 & 91.9 & 91.8 & 91.8 & 91.9 \\
\hline 1500 & 178.8 & 177.9 & 176.9 & 178.5 \\
\hline 1750 & 367.3 & 361.6 & 353.9 & 369.5 \\
\hline
\end{tabular}

In this section, it has been pointed out that one cubic element per member is sufficient to trace the nonlinear equilibrium path of the Williams' toggle and the post-bifurcation buckling 
path of the column depicted in Fig. 7. In both cases, the elastic buckling loads are accurately identified. It is also shown that one CR cubic element is able to accurately determine the second-order bending moments of the cantilevered column depicted in Fig. 9. These facts indicate the suitability of the cubic element for the design procedures based on second-order elastic analyses using notional horizontal forces [36], equivalent geometric imperfections [37] or modified tangent modulus [38]. In these analysis/design procedures, which directly capture the structural instability due to the $P-\Delta$ and $P-\delta$ effects, no use is made of the concept of effective length and thus rational buckling analysis is not required. When such design procedures are used, the perceived shortcoming of the cubic element in linear buckling analysis becomes irrelevant.

Three additional points regarding the use of cubic elements in the design of steel frames based on second-order elastic analysis can be made here. Firstly, cubic elements which are capable of modelling member imperfections have been presented [27-28, 39]. Secondly, in general only two cubic elements are required to accurately model each storey beam subjected to uniformly distributed loads. For practical steel design, the maximum bending moment within a member due to the $P$ - $\delta$ effect may be computed using a number of simple approaches described in the literature [8-9]. Thirdly, the cubic element which has been properly extended for three-dimensional analysis is also excellent for linear buckling analysis or second-order elastic analysis of steel frames whose members are liable to out-of-plane buckling. This issue is discussed further in Section 5.

\section{Second-order inelastic analysis and advanced analysis}

Second-order elastic analysis discussed in the preceding section is a significant improvement over linear (first-order) elastic analysis as the equilibrium calculations are based on the distorted topology of the structure. The use of second-order elastic analysis in the design of a steel frame obviates the need to perform linear buckling analysis and compute moment amplification factors for the determination of design bending moments in the members. This method of design is preferred over first-order elastic analysis since it is more straightforward and accurate in accounting for the stability interaction among individual members of the structure [40]. However, the assumption that the material is linearly elastic up until the strength limit state forms the drawback of second-order elastic analysis. In the limit states design, the strength check is performed independently on a member-by-member basis by 
comparing the elastic stress resultants with an ultimate (inelastic) strength interaction surface obtained by assuming some simplified model of the member behaviour. Thus the analysis and the design stages are incompatible [41-42]. Ziemian [41] and Bridge et al. [43] have also shown that second-order elastic analysis still leads to over-conservative design for certain structures.

Due to the shortcomings of the design procedures based on either first-order or second-order elastic analysis, advanced analysis has been widely touted as the state-of-the-art design method for the structural engineer in the new century. This method of analysis/design rigorously captures the interaction between the members of a structure which in general behaves nonlinearly before reaching its ultimate strength, allows for inelastic redistribution of internal forces from yielded members to the adjacent members, and accurately predicts the ultimate strength of a steel structure. Advanced analysis circumvents the cumbersome and often inaccurate practice in the design procedure based on first-order elastic analysis of determining the effective length of each compression member in a frame. The individual member capacity check, which must be carried out when either first-order or second-order elastic analysis is used to design a framed structure, is not required in advanced analysis [44]. An example of advanced analysis applications is the design of stressed-arch frames [45], for which the conventional design procedures are not rational. Furthermore, the use of advanced analysis to design steel frames may offer significant savings in construction costs as the member capacity checks in the conventional design procedures are generally overconservative [46-47].

In order to qualify as an advanced analysis method, a structural analysis/design model must be able to simulate the significant response phenomena associated with geometric and material nonlinearities of a steel structure. This requirement is tantamount to the use of second-order inelastic analysis [48-49]. Basically, in the context of steel frames, there are two types of second-order inelastic analysis: second-order plastic-hinge analysis and (secondorder) plastic-zone analysis. In between is the analysis based on the moment-thrust-curvature relationships. In plastic-zone analysis, the "gradual” spread of yielding across the monitored cross-section and along the element is modelled explicitly through numerical integration across the discretised cross-section located at selected integration points along the element. Conversely, in plastic-hinge based methods [5, 50-51], the point (usually an element end) where the stress resultants equal the local plastic capacity is assumed to be a zero-length 
hinge while the rest of the element remains elastic. The development of this plastic hinge is often "instantaneous" as the cross-section at the potential plastic hinge is usually assumed to be completely elastic until its full plastic capacity is exhausted.

In the past decade, considerable efforts have been spent to refine the plastic-hinge analysis method [38] since the limitations of the conventional plastic-hinge analysis method are well known [43, 52], and it is widely believed that the plastic-zone analysis method is too inefficient due to the large number of elements required to model a steel member. However, in most cases the application of refined plastic-hinge analysis has been limited to rectangular frames or to sections of certain geometry, although advanced analysis is supposed to facilitate the pursuit of more ingenious structural forms [42]. On the other hand, the concern regarding the inefficiency of the plastic-zone analysis method is losing validity for two reasons.

The first reason is that the plastic-zone analysis method using the beam element is not so inefficient as was previously believed. It is very likely that the erroneous belief had stemmed from the incorrect procedures used in determining the element forces, in addition to the tacit assumption of a straight configuration at the deformed reference state. Many publications have incorrectly stated that the nodal forces of a plastic-zone cubic element are computed through the integration of the cross-section stresses at the element ends. Such a procedure ignores the fact that the cubic element is a displacement-based finite element which does not necessarily satisfy the static boundary conditions [1]. As recently explained by Teh \& Clarke [53], the proper force recovery procedure of the plastic-zone cubic element involves integration over the volume of the element which results in satisfaction of the principle of virtual work.

For the Vogel's portal frame [54] depicted in Fig. 10, a total of 120 plastic-zone beam elements have been used in the literature. However, if the proper force recovery procedure is employed, then only 9 elements ( 4 for each column and 1 for the beam) are required to trace the nonlinear equilibrium path of the Vogel's portal frame accurately as shown in Fig. 11. The post-buckling path was not traced by Clarke [55] as the plastic-zone analysis using 120 elements was terminated at the ultimate load point. Depending on the algorithm employed to solve the system of simultaneous linear equations [11, 46], the use of 120 instead of 9 elements can mean a difference of the order of two or even three in analysis time. 


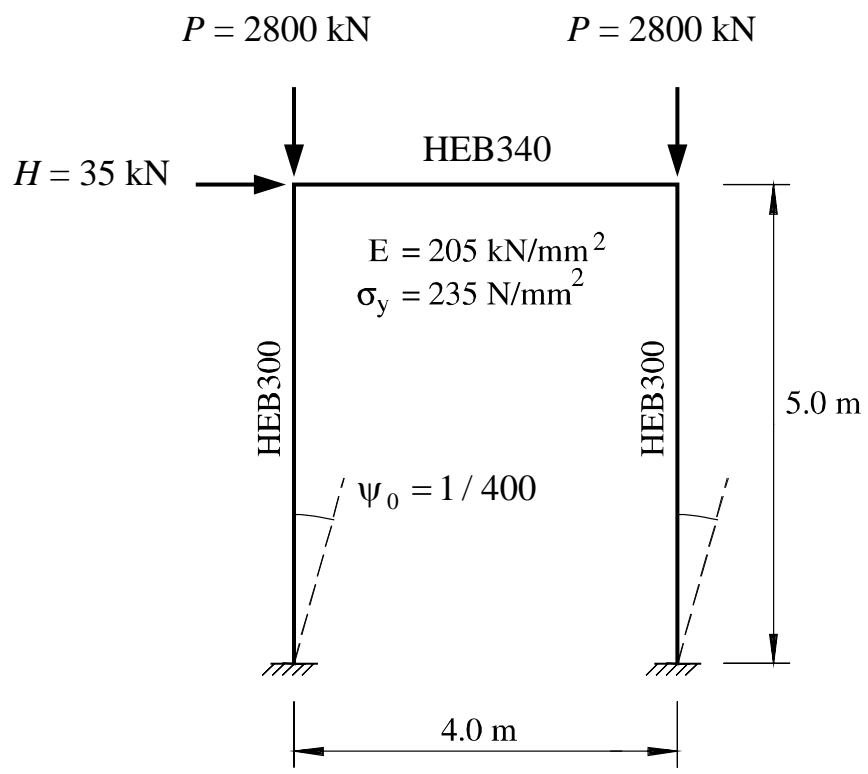

Fig. 10 Vogel’s portal frame [54]

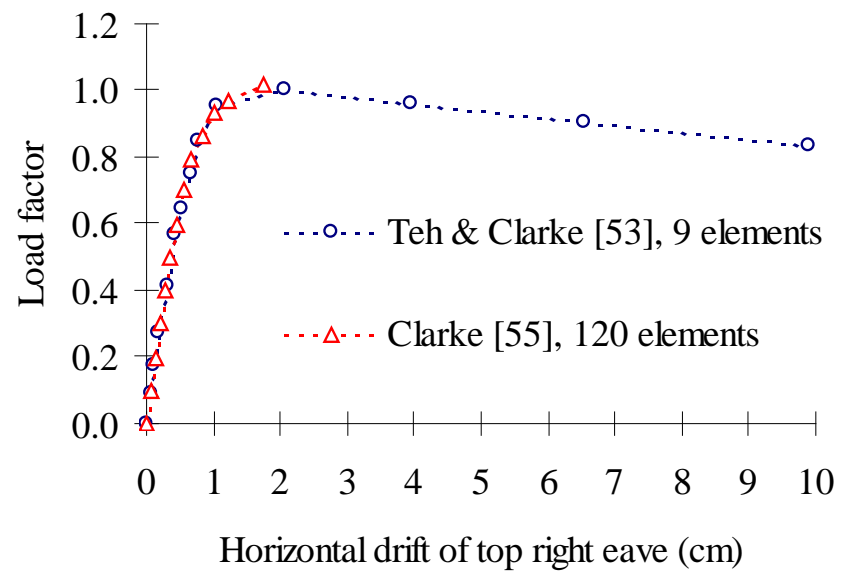

Fig. 11 Load-deflection graphs for Vogel’s portal frame

The second reason that the concern regarding the inefficiency of the plastic-zone analysis method is losing validity is an external factor. With rapid and continuous advances in desktop and laptop computer technology, the cost associated with the number of elements required to model a structure is becoming less and less an issue [38]. By the time the structural engineering profession becomes enthusiastic towards the concept of advanced analysis as a design philosophy (which may in turn be influenced by the availability of suitable computer software), the speed of personal computers is likely to overwhelm the forementioned concern even for large frames.

Compared to the refined plastic-hinge based analysis methods, the plastic-zone analysis method has several advantages. The effects of the inelastic flexural-torsional coupling on 
member three-dimensional response and of the inelastic interaction between axial force, biaxial bending and torsion on cross-sectional strength can be modelled more accurately in plastic-zone analysis. The plastic-zone model is also more versatile in accommodating the effects of specialised stress-strain characteristics and distributions of residual stresses such as those occurring in cold-formed steel tubes, since the force-based yield surfaces used in plastic-hinge analysis are typically calibrated for hot-rolled I-sections. Furthermore, the refined plastic-hinge based analyses may not satisfactorily describe the distributed inelastic behaviour of certain structures such as the stressed-arch frames [56].

The plastic-zone analysis method is also superior to the analysis method based on the moment-thrust-curvature relationships. This is because the path-dependent nature of inelastic behaviour and the concept of elastic unloading cannot be captured rigorously in this approach. Furthermore, the moment-thrust-curvature relationships are unique for a particular cross-section geometry, and depend on the stress-strain characteristics. Separate relations will also be required for tension and compression cases if the residual stresses are to be taken into account.

In summary, the most logical approach to advanced analysis/design of steel frames in the future is to use the plastic-zone analysis method. For this purpose, the cubic beam element has been demonstrated to be simple, accurate and efficient [53, 56-57]. In general, only three cubic elements are required to model a storey column, and four or five cubic elements are sufficient to model a fixed base column accurately [46, 53]. It should be noted that contrary to a recent statement [58], the goal of advanced analysis is not to utilise a frame analysis that represents each member with a single element. At present, advanced analysis/design of steel frames is restricted by design codes to planar frames composed of compact members that are not subjected to lateral buckling [44]. Notwithstanding this formal restriction, it appears that at least for space frames composed of compact tubular sections, advanced analysis based on the plastic-zone approach is now practically feasible [47, 53, 59].

\section{Three-dimensional analysis and “out-of-plane” buckling}

Springfield [42] stated that few if any current computer programs could deal with out-ofplane buckling of beams or beam-columns [60-62] by other than empirical means, and pointed out that if this empiricism only parallels the local design specification, then such 
advanced analysis will yield little advantage. Fortunately, the spatial cubic beam element has been shown to be versatile for detecting the torsional buckling of a column [25], the flexuraltorsional buckling of the members of a "plane” frame due transverse shear forces [63], the flexural-torsional buckling of the members of a spatial frame due to transferred bending moments [25], the flexural-torsional buckling of a mono-symmetric column [62], and the flexural buckling of a torsion member [64]. On the other hand, Hancock [17] pointed out that no stability functions had been developed for flexural-torsional instability. This situation remains true today and is likely to continue. This is because even if such stability functions were formulated, they would be restricted to members subjected to uniform moment as the differential equations of equilibrium under combined flexure and torsion have only been solved in closed forms for uniform moment.

Figure 12 compares the classical solutions [60] and the cubic element solutions [24] for the lowest elastic buckling loads of a simply supported hat section subjected to an axial load applied to the centroid. The two dashed lines in the figure plot the classical solutions for the flexural buckling loads $P_{\mathrm{x}}$ and $P_{\mathrm{y}}$ about the major and the minor axes, respectively. The lowest buckling mode of the hat section is flexural-torsional, and is dominated by the torsional mode, the classical buckling loads of which are denoted $P_{\mathrm{z}}$. It can be seen that the cubic element solutions, obtained using 2 elements for the braced member and denoted by crosses, are close to the classical solutions.

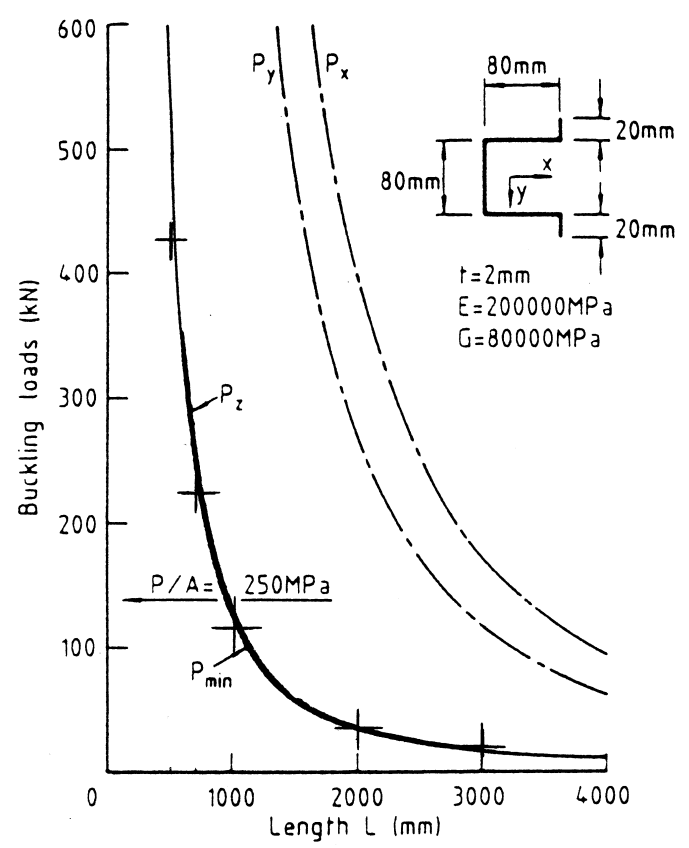

Fig. 12 Lowest buckling loads for simply supported hat section 
However, it should be cautioned that the beam elements or beam-columns available in most commercial frame analysis programs are not able to accurately detect the flexural-torsional buckling of column sections such as that depicted in Fig. 12. This is because shear-centre eccentricity and torsional warping are not normally accounted for in commercial frame analysis software, even though it may be claimed to have 3D nonlinear frame analysis capability. The formulations of cubic elements which address these two problems have been presented in the literature [65-70].

Figure 13 compares the classical solutions [60] and the cubic element solutions [24] for the lowest buckling loads of a simply supported angle section, for which the interaction between flexural and torsional buckling modes is more pronounced than the hat section. The cubic element again proves to be capable of capturing this interaction with only two elements.

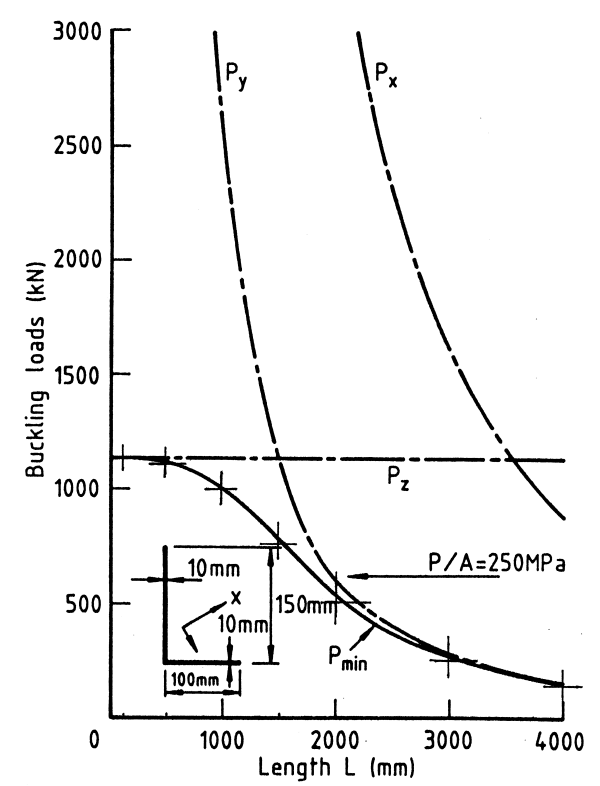

Fig. 13 Lowest buckling loads for simply supported angle section

It should also be noted that the cubic element formulation can detect the reduced flexuraltorsional buckling load of a beam due to off-centre transverse shear loadings [70-73].

\section{Conclusions}

The paper has discussed the concern regarding the shortcoming of the cubic element in the Euler buckling analysis of a simply supported column, which was recently quoted by some authors as a reason against its use in the structural analysis/design of steel frames. It was 
explained in the paper that only one cubic element is required for an unbraced member, and at most two for a braced member including a simply supported column. It was also demonstrated that only one cubic element per member is required to accurately predict the linear buckling load of a diagonally-braced multi-storey frame studied in the paper. For the sake of conservatism, two cubic elements may be used for each of the more critical members with little penalty on analysis time.

It was further pointed out that contrary to a recent claim, only one cubic element per member is required to accurately trace the nonlinear equilibrium path of the Williams' toggle. One cubic element is also sufficient to trace the post-bifurcation buckling path of a cantilevered column within the confines of practical usefulness, and to accurately determine the secondorder bending moments at the base of a cantilevered column. These facts, and the points made in the preceding paragraph, mean that the argument cited in recent literature that the cubic element is too inefficient for practical use is not well-founded. Note also that cubic elements capable of modelling member imperfections have been derived.

The paper has also discussed briefly the advantages of advanced analysis in the design of steel frames. In this regard, it was argued that the plastic-zone analysis method is superior to the plastic-hinge based analysis methods for a number of reasons. It was also pointed out that the plastic-zone analysis method using beam elements is not so inefficient as was previously believed. The concern regarding the need to employ several plastic-zone elements per member is fast becoming overwhelmed by the ever increasing speed of personal computers.

As pointed out by some visionary researchers, the cubic element is readily extended to threedimensional frame analysis accounting for the coupling between axial, flexural and torsional deformation modes. The cubic element has also been shown to be capable of detecting various modes of out-of-plane buckling. The cubic element is thus suitable for 2D and 3D design procedures based on linear elastic analysis, second-order elastic analysis, and secondorder inelastic analysis. The same cannot always be said of the elements or beam-columns proposed in recent years.

The fact that the easily overcome shortcoming of the cubic element is well documented should be a reason 'for' rather than 'against' its continuing use. In the context of the structural steel design procedure based on second-order elastic analysis or advanced analysis, either of which does not make use of the concept of effective length, the perceived 
shortcoming of the cubic element in linear buckling analysis is largely irrelevant. Therefore, the cubic element should continue to be a versatile and excellent beam element for the purpose of structural analysis/design of steel frames for many years to come.

\section{Acknowledgments}

The writer thanks Gregory Hancock and Tim Wilkinson for suggesting improvements to the manuscript. Thanks are also extended to William McGuire and Donald White for their vision and encouragement. The assumption of a straight configuration at the last deformed reference state of the Updated Lagrangian cubic element was brought to the author's attention by Donald White and Murray Clarke. Any opinions expressed in the paper are those of the writer, and do not necessarily reflect the views of the writer's colleagues. The writer also thanks Kim Pham for the prompt production of some illustrations used in the paper. 


\section{Appendix I. Geometric nonlinearity due to the $P-\delta$ and $P-\Delta$ effects}

There are two primary sources of geometric nonlinearity in a gravity loaded framed structure, known as the $P-\delta$ effect and the $P-\Delta$ effect. These two effects are illustrated in Fig. I.1. As can be seen from the figure, the $P-\delta$ effect is due to the member flexure while the $P-\Delta$ effect arises from the rigid body rotation (also known as the chord rotation) of the member. For the members of a frame, the $P-\Delta$ effect is due to the joint translations and is present mainly in sway frames. The $P-\Delta$ effect is therefore generally understood to be associated with frame instability, while the $P-\delta$ effect is associated with member instability [8]. However, as far as an element is concerned, the $P-\Delta$ effect may also be present in a braced member that is modelled with two or more elements, as illustrated in Fig. I.2.

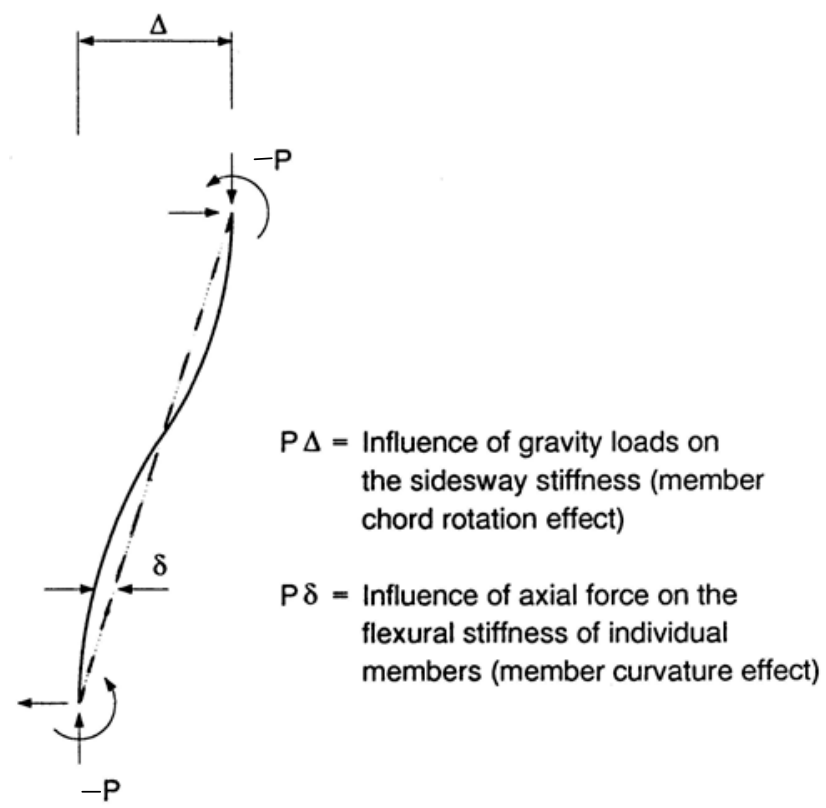

Fig. I.1 The $P-\delta$ and $P-\Delta$ effects of a beam-column [9]

The inaccuracy of the cubic element is with respect to the modelling of the $P-\delta$ effect rather than the $P-\Delta$ effect. This is because the cubic interpolation function $\mathbf{N}$ for the transverse displacements $v$ along the reference line of a two-noded beam element

$$
\begin{aligned}
& v(x)=\mathbf{N}\left\{\begin{array}{llll}
v_{a} & L \theta_{a} & v_{b} & L \theta_{b}
\end{array}\right\}^{\mathrm{T}} \\
& \mathbf{N}=\left\{1-3\left(\frac{x}{L}\right)^{2}+2\left(\frac{x}{L}\right)^{3}\left(\frac{x}{L}\right)-2\left(\frac{x}{L}\right)^{2}+\left(\frac{x}{L}\right)^{3} 3\left(\frac{x}{L}\right)^{2}-2\left(\frac{x}{L}\right)^{3}\left(\frac{x}{L}\right)^{3}-\left(\frac{x}{L}\right)^{2}\right\}
\end{aligned}
$$




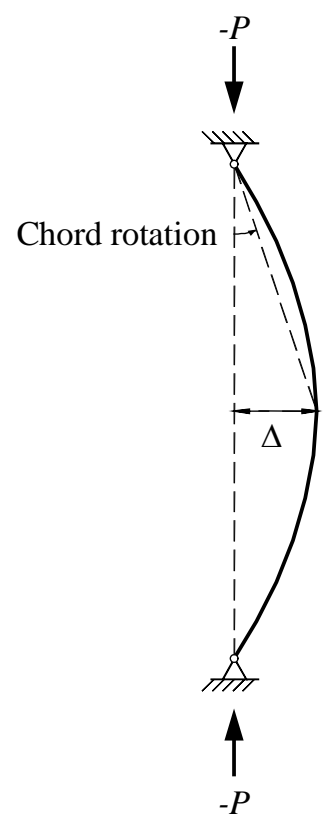

Fig. I.2 The $P-\Delta$ effect in a braced member divided into two elements

in which

$x \quad=$ distance from node A, where $x_{\mathrm{a}}=0$;

$L \quad$ = element length;

$v_{\mathrm{a}}, v_{\mathrm{b}}=$ transverse displacements of node $\mathrm{A}$ and node $\mathrm{B}$, respectively;

$\theta_{\mathrm{a}}, \theta_{\mathrm{b}}=$ rotations of node $\mathrm{A}$ and node $\mathrm{B}$, respectively;

is strictly valid for the linearly elastic member that is subjected to a linear variation of bending moments. Due to the $P$ - $\delta$ effect, which induces second-order bending moments, the bending moments do not vary linearly along a beam-column. On the other hand, the cubic interpolation function is exact as far as the chord rotation is concerned.

When both effects are present, the geometric nonlinearity is generally dominated by the $P-\Delta$ effect rather than the $P-\delta$ effect. This phenomenon manifests in the Euler buckling analysis results of a simply supported column and a sway column (third from right in Fig. 1), which have the same theoretical effective length factor of unity. It can be seen from Fig. 1 that a simply supported column, when modelled with one element, is not subjected to the $P-\Delta$ effect and so the cubic element must simulate the $P-\delta$ effect only. Due to the inaccuracy of the cubic shape function mentioned previously, the error in the predicted Euler buckling load is $21.6 \%$, which corresponds to the approximation of $\pi^{2}$ by 12 in the eigenvalue solution. 
Conversely, a sway column undergoes a chord rotation upon buckling and is hence subjected to the $P-\Delta$ effect, which largely overwhelms the $P-\delta$ effect. Since the cubic shape function is exact for the chord rotation, the error in the predicted Euler buckling load of a sway column is less than $1 \%$, even though only one cubic element is used.

If a simply supported column is modelled with two cubic elements as shown in Fig. I.2, then for each element the $P-\Delta$ effect will be present and dominate the $P$ - $\delta$ effect. In this case, the error in the predicted Euler buckling load greatly reduces to less than $0.5 \%$. For the case of a built-in column, the use of two cubic elements also leads to an error of less than $0.5 \%$. Therefore, it can inferred that in general at most two cubic elements per column are required for an accurate linear buckling analysis of a framed structure. For a sway frame, only one cubic element per column is necessary.

In fact, as illustrated in Section 2, it is often feasible to model each column of a diagonally braced multi-storey frame with one cubic element only to obtain an accurate linear buckling load factor. 


\section{Appendix II. Stiffness matrices of an “impaired” UL cubic element}

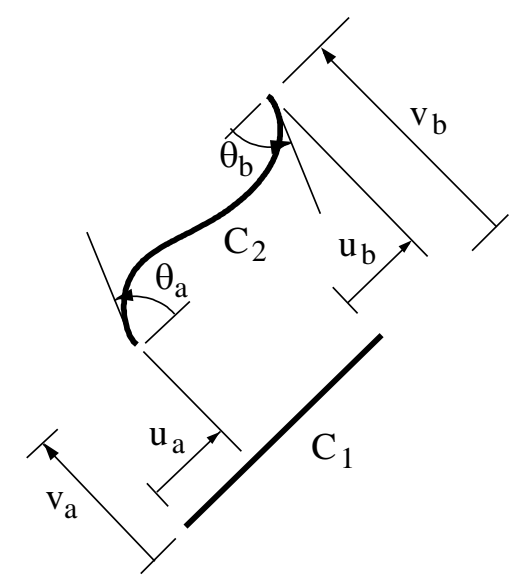

Fig. II.1 Displacement variables in UL formulation of a planar beam element assuming a straight configuration at $\mathrm{C}_{1}$

The nodal force increments $\Delta \mathbf{f}$ of a UL cubic element which assumes a straight configuration at $C_{1}$ is often determined from the tangent stiffness matrix ${ }^{1} \mathbf{k}_{\mathrm{T}}$ and the incremental nodal displacements $\mathbf{u}$ defined in Fig. II.1 as

$$
\Delta \mathbf{f}={ }_{1}^{2} \mathbf{f}-{ }^{1} \mathbf{f}={ }^{1} \mathbf{k}_{\mathrm{T}} \mathbf{u}
$$

in which the left superscript denotes the configuration at which the variable is determined, and the left subscript denotes the reference configuration. If the left subscript is not present, then the reference configuration is the same as the configuration at which the variable is determined. Normally, the incremental nodal displacement vector of a planar beam element is expressed as

$$
\mathbf{u}=\left\{\begin{array}{llllll}
u_{a} & v_{a} & \theta_{a} & u_{b} & v_{b} & \theta_{b}
\end{array}\right\}
$$

and the corresponding nodal force vector $\mathbf{f}$ as

$$
\mathbf{f}=\left\{\begin{array}{llllll}
F_{x a} & F_{y a} & M_{z a} & F_{x b} & F_{y b} & M_{z b}
\end{array}\right\}
$$

in which $F_{\mathrm{xa}}$ and $F_{\mathrm{xb}}$ are the nodal axial forces, $F_{\mathrm{ya}}$ and $F_{\mathrm{yb}}$ are the nodal transverse shear forces, and $M_{\mathrm{za}}$ and $M_{\mathrm{zb}}$ are the nodal bending moments. 
The tangent stiffness matrix $\mathbf{k}_{\mathrm{T}}$ can be decomposed into the linear stiffness matrix $\mathbf{k}_{\mathrm{L}}$ and the geometric stiffness matrix $\mathbf{k}_{\mathrm{G}}$

$$
\mathbf{k}_{\mathrm{T}}=\mathbf{k}_{\mathrm{L}}+\mathbf{k}_{\mathrm{G}}
$$

both of which are symmetric for a planar cubic beam element.

The linear stiffness matrix is

$$
\mathbf{k}_{\mathrm{L}}=\left[\begin{array}{ccccc}
\frac{E A}{L} & & & -\frac{E A}{L} & \\
\\
& \frac{12 E I}{L^{3}} & \frac{6 E I}{L^{2}} & -\frac{12 E I}{L^{3}} & \frac{6 E I}{L^{2}} \\
& \frac{4 E I}{L} & & -\frac{6 E I}{L^{2}} & \frac{2 E I}{L} \\
& & \frac{E A}{L} & \frac{12 E I}{L^{3}} & -\frac{6 E I}{L^{2}} \\
& & & \frac{4 E I}{L}
\end{array}\right]
$$

and the geometric stiffness matrix is

$$
\mathbf{k}_{\mathrm{G}}=\left[\begin{array}{ccccc}
\frac{F_{x b}}{L} & -\frac{M_{z a}}{L} & -\frac{F_{x b}}{L} & & -\frac{M_{z b}}{L} \\
\frac{1.2 F_{x b}}{L}+\frac{12 F_{x b} I}{A L^{3}} & \frac{F_{x b}}{10}+\frac{6 F_{x b} I}{A L^{2}} & -\frac{1.2 F_{x b}}{L}+\frac{12 F_{x b} I}{A L^{3}} & \frac{F_{x b}}{10}+\frac{6 F_{x b} I}{A L^{2}} \\
& \frac{2 F_{x b} L}{15}+\frac{4 F_{x b} I}{A L} & \frac{M_{z a}}{L} & -\frac{F_{x b}}{10}-\frac{6 F_{x b} I}{A L^{2}} & \frac{-F_{x b} L}{30}+\frac{2 F_{x b} I}{A L} \\
& & \frac{F_{x b}}{L} & \frac{1.2 F_{x b}}{L}+\frac{12 F_{x b} I}{A L^{3}} & -\frac{F_{x b}}{10}-\frac{6 F_{x b} I}{A L^{2}} \\
& & & \frac{2 F_{x b} L}{15}+\frac{4 F_{x b} I}{A L}
\end{array}\right]
$$

in which $E, A, I$ and $L$ are the Young's modulus, the cross-section area, the second moment of area and the length of the beam element, respectively. 


\section{Appendix III. Secant stiffness relations for a CR cubic element}
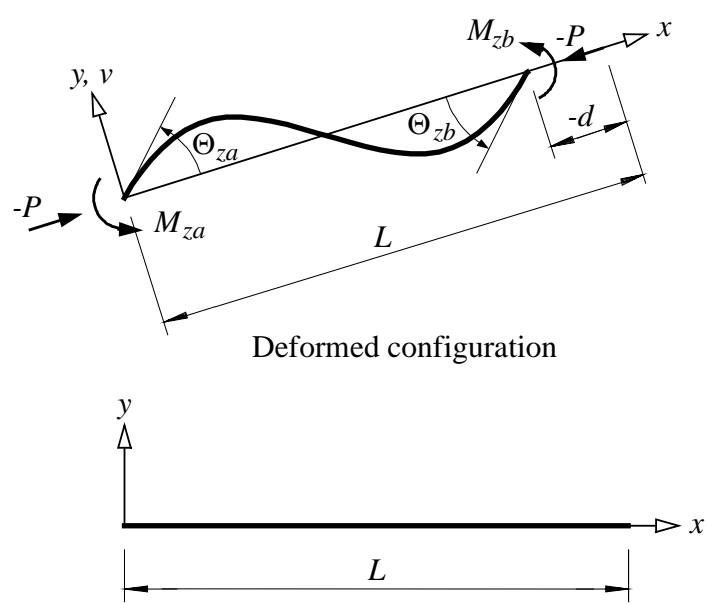

Undeformed configuration

Fig. III.1 Force and displacement variables in the CR formulation of a planar beam element

The secant relations between the forces and the deformations of a CR cubic beam element can be written as

$$
\begin{aligned}
& P=\frac{E A}{L}\left[d+\frac{L}{30}\left(2 \Theta_{z a}{ }^{2}-\Theta_{z a} \Theta_{z b}+2 \Theta_{z b}{ }^{2}\right)\right] \\
& M_{z a}=\left(\frac{4 E I}{L}+\frac{4 P L}{30}\right) \Theta_{z a}+\left(\frac{2 E I}{L}-\frac{P L}{30}\right) \Theta_{z b} \\
& M_{z b}=\left(\frac{2 E I}{L}-\frac{P L}{30}\right) \Theta_{z a}+\left(\frac{4 E I}{L}+\frac{4 P L}{30}\right) \Theta_{z b}
\end{aligned}
$$

in which $P$ is the element axial force, and $M_{\mathrm{za}}$ and $M_{\mathrm{zb}}$ are the nodal bending moments, as defined in Fig. III.1. The corresponding displacement variables $d, \Theta_{\mathrm{za}}$ and $\Theta_{\mathrm{zb}}$ are also defined in the figure.

The nodal transverse shear forces $F_{\mathrm{ya}}$ and $F_{\mathrm{yb}}$ can be computed based on the static equilibrium of a beam element

$$
F_{y a}=-F_{y b}=\frac{M_{z a}+M_{z b}}{L+d}
$$




\section{References}

[1] Cook R. D., Malkus D. S., Plesha M. E. Concepts and Applications of Finite Element Analysis. $3^{\text {rd }}$ ed. New York: John Wiley \& Sons, 1989.

[2] Gallagher R. H., Padlog J. Discrete element approach to structural instability analysis. AAIA J., 1963; 1:1437-1439.

[3] Przemieniecki J. S. Theory of Matrix Structural Analysis. New York: McGraw-Hill, 1968.

[4] Jennings A. Frame analysis including change in geometry. J. Struct. Div., ASCE, 1968; 94:627-644.

[5] Porter F. L., Powell G. H. Static and dynamic analysis of inelastic framed structures, Report No. EERC 71-3. Earthquake Engineering Research Centre, University of California at Berkeley, California, 1971.

[6] Chajes A., Churchill J. E. Nonlinear frame analysis by finite element method. J. Struct. Engrg., 1987; 113:1221-1235.

[7] Gattass M., Abel J. F. Equilibrium considerations of the Updated Lagrangian formulation of beam-columns with natural concepts. Int. J. Numer. Meth. Engrg., 1987; 24:21192141.

[8] Chen W. F., Lui E. M. Stability Design of Steel Frames, Boca Raton (FL): CRC Press, 1991.

[9] White D. W., Hajjar J. Application of second-order elastic analysis in LRFD: research to practice. Engrg. J., AISC, 1991; 28:133-148.

[10] Yang Y. B., Leu L. J. Non-linear stiffnesses in analysis of planar frames. Comp. Meth. Appl. Mech. Engrg., 1994; 117:233-247.

[11] McGuire W., Gallagher R. H., Ziemian R. Matrix Structural Analysis. $2^{\text {nd }}$ ed. New York: John Wiley \& Sons, 2000.

[12] Livesley R. K., Chandler D. B. Stability Functions for Structural Frameworks, England: Manchester University Press, 1956.

[13] Renton J. D. Stability of space frames by computer analysis. J. Struct. Div., ASCE, 1962; 88(4):81-103.

[14] Saafan S. A. Nonlinear behaviour of structural plane frames. J. Struct. Div., ASCE, 1963; 89:557-579.

[15] Horne M. R., Merchant W. Stability of Frames, Oxford: Pergamon Press, 1965. 
[16] Harrison H. B. Plastic design in high strength steel: The second-order elastic analysis of plane rigid frames, Fritz Engineering Laboratory Report No. 297.17, Lehigh University, Bethlehem, PA, 1965.

[17] Hancock G. J. Elastic method of analysis of rigid jointed frames including second order effects. Journal of the Australian Institute of Steel Construction, 1994; 28(3):10-18.

[18] McGuire W., Ziemian R. Discussion of 'Second-order elastic analysis for frame design' by Y. Goto and W. F. Chen, J. Struct. Engrg., 1988; 114:501-503.

[19] Goto Y., Chen W. F. Second-order elastic analysis for frame design. J. Struct. Engrg., 1987; 113:1501-1519.

[20] Izzuddin B. A. Quartic formulation for elastic beam-columns subject to thermal effects. J. Engrg. Mech., 1996; 122:861-871.

[21] Chan S. L., Zhou Z. H. Nonlinear integrated design and analysis of skeletal structures by 1 element per member. Engrg. Struct., 2000; 22:246-257.

[22] Liew J. Y. R., Chen H., Shanmugam N. E., Chen W. F. Improved nonlinear plastic hinge analysis of space frame structures. Engrg. Struct., 2000; 22:1324-1338.

[23] McGuire W. Computers and steel design. Engrg. J., AISC, 1992; 29:160-169.

[24] Teh L. H. Nonlinear Inelastic Space Frame Analysis (NISFA). Centre for Advanced Structural Engineering, University of Sydney, Australia, 2000.

[25] Teh L. H., Clarke M. J. Co-rotational and Lagrangian formulations of elastic threedimensional beam finite elements. J. Construct. Steel Res., 1998; 48:123-144.

[26] Williams F. S. An approach to the nonlinear behaviour of the members of a rigid jointed plane framework with finite deflections. Quart. J. Mech. Appl. Math., 1964; 17:451-469.

[27] Gattass M., Abel J. F. Convected systems for curved structural elements. Int. J. Numer. Meth. Engrg., 1987; 24:2143-2166.

[28] Clarke M. J. The behaviour of stressed-arch frames, PhD thesis. School of Civil and Mining Engineering, University of Sydney, Sydney, 1992.

[29] Crisfield M. A. A fast incremental/iterative solution procedure that handles snap-through. Comp. Struct., 1981; 13:55-62.

[30] Chan S. L. Geometric and material nonlinear analysis of beam columns and frames using the minimum residual displacement method. Int. J. Numer. Meth. Engrg., 1988; 26:26572669.

[31] Oran C. Tangent stiffness in plane frames. J. Struct. Div., ASCE, 1973; 99:973-985. 
[32] Yang, Y. B., Wu, S. W., and Kuo, S. R. An effective strategy for post-buckling analysis of structures. Proc., Lightweight Structures in Architecture, Engineering and Construction, 5-9 October 1998, Sydney, Australia, 384-392.

[33]Teh L. H., Clarke M. J. Tracing the secondary equilibrium paths of elastic framed structures. J. Engrg. Mech., 1999; 125:1358-1364.

[34] Timoshenko S. P., Gere J. M. Theory of Elastic Stability. $2^{\text {nd }}$ ed. New York: McGrawHill, 1961.

[35] Hancock G. J. Second order elastic analyses: Solution techniques and verification. Journal of the Australian Institute of Steel Construction, 1994; 28(3):19-25.

[36] Clarke M. J., Bridge R. Q. The notional load approach for the design of frames, Research Report No. R718. School of Civil and Mining Engineering, University of Sydney, Sydney, 1995.

[37] Oda H., Usami T. Stability design of steel plane frames by second-order elastic analysis. Engrg. Struct., 1997; 8:617-627.

[38] Chen W. F. Structural stability: from theory to practice. Engrg. Struct., 2000; 22:116-122.

[39]Hsiao, K. M., Hou, F. Y. Nonlinear finite element analysis of elastic frames. Comp. Struct., 1987; 26:693-701.

[40] Canadian Standards Association. Steel Structures for Buildings (Limit States Designs), CAN-S16, 1-M84, Rexdale, Ontario, 1984.

[41]Ziemian R. D. Advanced methods of inelastic analysis in the limit states design of steel structures, PhD thesis. Department of Civil and Environmental Engineering, Cornell University, New York, 1990.

[42] Springfield J. Foreword. Plastic Hinge Based Methods for Advanced Analysis and Design of Steel Frames, D. W. White and W. F. Chen, eds., SSRC, Lehigh University, Pennsylvania, 1993; i-ii.

[43]Bridge R. Q., Clarke M. J., Hancock G. J., Trahair N. S. Trends in the analysis and design of steel building frames. Civ. Engrg. Trans., IEAust, 1991; CE33:87-95.

[44] Standards Australia. Steel Structures: AS 4100, Homebush, New South Wales, 1998.

[45] Clarke M. J., Hancock G. J. Design of top chord of stressed-arch frames. J. Struct. Engrg., 1995; 121:201-213.

[46]Teh L. H. Towards 3D plastic-zone advanced analysis of steel frames, PhD thesis. Department of Civil Engineering, University of Sydney, Australia, 1998. 
[47] Teh L. H., Clarke M. J. Advanced analysis of steel frames composed of tubular sections-A preliminary case study. Proc., $5^{\text {th }}$ Pacific Structural Steel Conf., Seoul, 13-16 October 1998, Dong-Il Chang et. al., eds., Techno-Press, Seoul, 277-282.

[48] Clarke M. J., Bridge R. Q., Hancock G. J., Trahair N. S. Advanced analysis of steel building frames. J. Construct. Steel Res., 1992; 23:1-29.

[49] Ziemian R. D., McGuire W., Deierlein G. G. Inelastic limit states design. Part I: Planar frame study. J. Struct. Engrg., 1992; 118:2532-2549.

[50] Heyman J. Plastic Design of Portal Frames, England: Cambridge University Press, 1957.

[51] Orbison J. G., McGuire W., Abel J. F. Yield surface applications in nonlinear steel frame analysis. Comp. Meth. Appl. Mech. Engrg., 1982; 33:557-573.

[52] McGuire W. Refining the plastic hinge concept. Proc., 1991 Annual Technical Session: Inelastic Behaviour and Design of Frames, Chicago, Illinois, 15-17 April 1991, SSRC, Lehigh University, Pennsylvania, 1-12.

[53] Teh L. H., Clarke M. J. Plastic-zone analysis of 3D steel frames using beam elements. J. Struct. Engrg., 1999; 125:1328-1337.

[54] Vogel U. Calibrating frames. Stahlbau, 1985; 54:295-301.

[55] Clarke M. J. Plastic-zone analysis of frames. Advanced Analysis of Steel Frames, W. F. Chen and S. Toma, eds., Boca Raton (FL): CRC Press, 259-319, 1994.

[56] Clarke M. J., Hancock G. J. Finite element nonlinear analysis of stressed-arch frames. J. Struct. Engrg., 1991; 117:2819-2837.

[57] Izzuddin B. A., Lloyd Smith D. Large-displacement analysis of elastoplastic thin-walled frames. II: Verification and application. J. Struct. Engrg., 1996; 122:915-925.

[58] Nethercot D. A. Frame structures: global performance, static and stability behaviour. General report. J. Construct. Steel Res., 2000; 55:109-124.

[59] Hori A., Sasagawa A. Large deformation of inelastic large space frame. II: Application. J. Struct. Engrg., 2000; 126:589-595.

[60] Trahair N. S. Flexural-Torsional Buckling of Structures, London: E\&FN Spon, 1993.

[61] McGuire, W., Ziemian, R. Steel frame stability: Out-of-plane effects. Proc., First Int. Conf. Structural Stability and Dynamics, Taipei, Taiwan, 7-9 December 2000, 5-20.

[62] Teh L. H., Hancock G. J., Clarke M. J. Analysis and design of high-rise steel pallet rack frames, Research Report. Department of Civil Engineering, University of Sydney, Australia, 2000. 
[63] Papangelis J. P., Trahair N. S., Hancock G. J. Elastic flexural-torsional buckling of structures by computer. Comp. Struct., 1998; 68:125-137.

[64] Trahair N. S., Teh L. H. Second-order moments in torsion members. Engrg. Struct., 2001; 23:631-642.

[65]Barsoum R. S., Gallagher R. H. Finite element analysis of torsional and flexuraltorsional stability problems. Int. J. Numer. Meth. Engrg., 1970; 2:335-352.

[66]Hancock G. J., Trahair N. S. Finite element analysis of the lateral buckling of continuously restrained beam-columns. Civ. Engrg. Trans., IEAust, 1978; CE20:120-127.

[67] Attard M. Lateral buckling analysis of beams by FEM. Comp. Struct., 1986; 23:217-231.

[68] Conci A. Large displacement analysis of thin-walled beams with generic open section. Int. J. Numer. Meth. Engrg., 1992; 33:2109-2127.

[69] Rajasekaran S. Equations for tapered thin-walled beams of generic open section. J. Engrg. Mech., 1994; 120:1607-1629.

[70]Hsiao K. M., Lin W. Y. A Co-rotational formulation for thin-walled beams with monosymmetric open sections. Comp. Meth. Appl. Mech. Engrg., 2000; 190:1163-1185.

[71]Bradford M. A. Elastic buckling of tapered mono-symmetric I-beams. J. Struct. Engrg., 1988; 114:977-996.

[72]Pi Y. L., Trahair N. S., Rajasekaran S. Energy equation for beam lateral buckling. J. Struct. Eng., 1992; 118:1462-1479.

[73] Kim M. Y., Chang S. P., Kim S. B. Spatial post-buckling analysis of non-symmetric thinwalled space frames, accepted for publication in J. Engrg. Mech., ASCE. 